\title{
La utilidad social de la información producida por la radiodifusión canaria durante el franquismo, 1939-1975
}

institucional.us.es/ambitos/

\section{Julio Antonio Yanes Mesa}

Universidad de La Laguna

jayanes@ull.edu.es

English Version: The social usefulness of the information produced by the Canarian broadcasting during the Franco.

\section{Resumen}

En el franquismo, la prohibición de informar al margen de los Diarios hablados de

Radio Nacional de España no impidió a las emisoras hacerlo coyunturalmente en ciertos programas de producción interna. En el caso del archipiélago canario, a ello coadyuvó la lejanía de Madrid, el liberalismo de la idiosincrasia insular, el rechazo de las tesis autárquicas del régimen y la debilidad del falangismo. Aún así, el uso exclusivo de las fuentes oficiales y la autocensura lastraron la utilidad social de tales iniciativas, salvo en la gestión de las catástrofes, en las que la radio jugó, en combinación con los radioaficionados, un papel de primer orden.

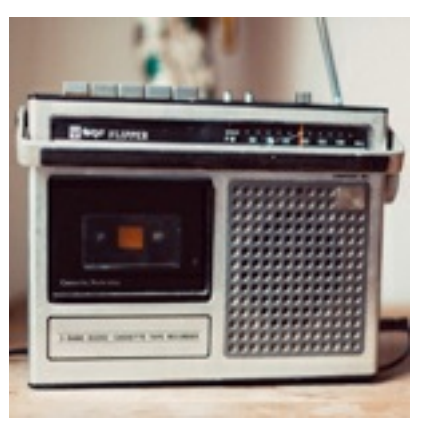

\section{Palabras clave}

Franquismo, información radiofónica, periferias, Islas Canarias.

\section{Abstract}

During Franquism, prohibition to inform apart from the Daily spoken news bulletin of Radio Nacional de España did not prevent the broadcasting entities to give news occasionally in some programmes of internal production. In

the case of the Canary Islands, this situation was reinforced due to the distance of Madrid, the liberalism of the

Canary Islands idiosyncrasy, the rejection of the autocratic thesis of the regime and the weakness of the Falangists. Even then, the unique use of the official sources and self-censorship debilitated the social usefulness of those initiatives, except in the management of disasters, where the radio played a fundamental role, in combination with amateur radio enthusiasts.

Keywords

Franquism, radio-broadcasting news, outskirts, Canary Islands.

\section{INTRODUCCIÓN}

Durante el franquismo, las emisoras españolas tuvieron prohibido dar todo tipo de información al margen de los Diarios hablados de Radio Nacional de España que, preceptivamente, retransmitían por la mañana, al mediodía y a primeras horas de la noche (Díez, 2008: 116). La rotundidad de la disposición y la férrea censura de la época hacen explicable que, al darse por descontado el logro del objetivo por el legislador, los estudiosos del medio no hayan reparado en la utilidad social de las iniciativas que, al respecto, pudieron acometer las propias emisoras en sus programas de producción interna. Algunos autores han sacado a la luz referencias tangenciales sobre "espacios de contenido informativo tolerados por la Dirección General de Radiodifusión" (Balsebre, 2002: 227) que, desde los años cincuenta, ofrecían dos de las estaciones más pujantes de la cadena SER, Radio Madrid EAJ-7 y Radio Bilbao $E A J-28$, en los cuales se llegaron a criticar los servicios públicos y los problemas urbanos de las respectivas ciudades. Las preguntas de investigación que nos sugiere el dato, más que en los enclaves desarrollados del país, nos hacen pensar en los periféricos y marginales, en donde las emisoras estaban mucho más volcadas 
sobre sus audiencias locales y, dadas sus reducidas coberturas, menos expuestas a los rigores del régimen.

A la vista del estado de la cuestión, nos hemos propuesto analizar los programas de producción interna que, de una u otra manera, tuvieron algo que ver con labores informativas en la radiodifusión de la provincia de Santa Cruz de Tenerife. El marco geográfico referido nos viene dado por la línea de investigación que, desde hace una década, tenemos abierta sobre el subsistema radiofónico canario dentro del español durante el franquismo, al objeto de enriquecer, con la aportación de las especificidades isleñas, el estado actual de los conocimientos sobre la Historia del medio en España. Tal planteamiento está justificado por el marcado hecho diferencial del archipiélago en el contexto estatal debido a la insularidad, la lejanía, la tardía incorporación al mundo occidental en el siglo XV, la subsiguiente apertura de la economía insular al exterior (Macías \& Rodríguez, 1995: 369-398) y, como seña ideológica que siempre ha reflejado la prensa autóctona (Yanes, 2003: 551-556), el pragmatismo y el liberalismo de la idiosincrasia isleña. Por de pronto sabemos que, durante la dictadura franquista, tales rasgos diferenciales se tradujeron en la desafección a la política autárquica del régimen (Guerra, 2005) y en la escasísima implantación de Falange en las islas (León, 2015). (01)

Sobre tales premisas, el objetivo que nos hemos planteado ha sido el de calibrar, conforme transcurrieron los años, la dimensión informativa en los espacios de producción propia relacionados con la actualidad, evidentemente, dentro del discurso propagandístico que embadurnaba todo lo que salía al aire de las emisoras españolas. Las dos variables observadas y ponderadas a tal fin han sido, de un lado, la carga doctrinaria de los contenidos y, de otro, la militancia política y la ideología de los guionistas y colaboradores de tales espacios. La vaguedad de nuestro objeto de estudio por la volatilidad de las ondas hertzianas y la ausencia de grabaciones en cinta magnetofónica de las emisiones, nos han obligado a echar mano de, algo así como, del "paradigma indiciario" de Carlo Ginzburg (Aguirre, 2014: 163-204) a la hora de recopilar los datos empíricos para poder asumir el reto. Con esas referencias discontinuas recabadas en las fuentes hemerográficas, archivísticas y orales sobre lo sucedido, hemos operado inductiva y deductivamente para reconstruir, con las inferencias realizadas sobre tales fragmentos de la realidad, los hechos con los que hemos dado cuenta del grado de consecución de los objetivos propuestos.

\section{EL PAULATINO RETROCESO DE LA PROPAGANDA IDEOLÓGICA EN LA PARRILLA DE LA PROGRAMACIÓN DURANTE EL PRIMER FRANQUISMO}

Tras la guerra civil, los primeros espacios de ámbito local abiertos, en alguna medida, a la información e, incluso, la opinión, aparecieron enla única emisora que funcionaba en la provincia occidental del archipiélago canario, Radio Club Tenerife, a los dos años y medio de la conclusión de la lucha fratricida, cuando la evolución de la II Guerra Mundial era todavía favorable a la Alemania nazi. Tan temprano hito resulta comprensible a la luz del perfil de su artífice, el locutor Arturo Navarro Grau, un joven periodista tinerfeño que había combatido como voluntario en el bando rebelde durante la guerra civil y adquirido una cierta experiencia como propagandista de la causa en la "emisora ambulante" enviada desde Tenerife al frente de Cataluña (Yanes, 2011: 101-116). Sin duda alguna, el hecho de tratarse de una persona de absoluta confianza de las autoridades insulares es lo que hace explicable la reaparición de este tipo de formatos, utilizados por Radio Club Tenerife en la II República para posibilitar el intercambio de pareceres, dado que ahora tenían una orientación inequívocamente propagandística.

El primero de estos espacios, titulado "Las interviús radiofónicas", fue muy bien recibido desde su aparición, el28 de octubre de 1941, por la agilidad que la sucesión de preguntas y respuestas introdujo entre un público acostumbrado a las monolíticas peroratas con las que se había hecho propaganda durante la guerra civil. Al margen de los cuadros del partido único, el grueso de los entrevistados pertenecían al mundillo cultural isleño, evidentemente, tras la purga oportuna, caso del presidente de la Escuela de Arte de Tenerife, el vivero del teatro radiofónico y los sesudos programas culturales de la época, o del director de la Orquesta de Cámara de Canarias. En meses sucesivos, el propio Arturo Navarro Grau sacó al aire una"Galería radiofónica de nuestros artistas"con un tono similar, aunque más ceñido aún a la "cultura" en la acepción más exquisita del término; así como unas "encuestas" que llevaban por título “¿Qué opina Vd. del micrófono y su trascendencia?” o “¿Qué opina Vd. del progreso artístico deTenerife?”, en las que también intervinieron "numerosos literatos y artistas del 
país o radicados en nuestra isla". Estos espacios, todavía en manos de los militantes del régimen, llegaron en el prime time nocturno a los tres millares escasos de hogares isleños que, por entonces, podían permitirse el lujo de contar con un aparato receptor de radio (Yanes, 2012: 143-150).

En la década siguiente, Arturo Navarro Grau tenía en antena, bajo el título"Charlas de los jueves", otras "conversaciones con invitados" a primeras horas de la noche. El continuismo con los espacios anteriores está ilustrado tanto en el perfil del entrevistador como en el de los entrevistados que más llamaron a atención de la prensa. A saber, el periodista y escritor vasco Jacinto Miquelarena Regueiro (1891-1962), quien fuera director de Radio Nacional de España en Salamanca durante la guerra civil, que visitó la isla en marzo de 1956; el periodista tinerfeño afín al régimen, y censor de la emisora, Antonio Marti (1901-1986), el cual habló a finales de marzo de 1958 del proyecto de construcción de varias "instalaciones turísticas en el litoral de Santa Cruz", en lo que debió ser uno de los primeros movimientos de la burguesía ante el inminente despegue del turismo de masas; o el "diplomático y escritor" catalán Gonzalo Fernández de la Mora (1924-2002), quien habría de ocupar el Ministerio de Obras Públicas a finales del franquismo, cuando en septiembre de 1958 vino a Tenerife como mantenedor de una fiesta literaria (Yanes, 2012: 204-206).

No obstante, desde la conclusión de la II Guerra Mundial estaba quedando cada vez más en evidencia el escaso número de propagandistas del régimen que tenía en plantilla la emisora, reducidos a los locutores Arturo Navarro Grau, Victoriano Francés Suárez (quien leyera el bando de Franco en la madrugada del 18 de julio) y poco más, frente a la pléyade de escritores y artistas que, sin afán proselitista alguno, acudían a los estudios por el simple hecho de dar satisfacción a sus inquietudes culturales. Es más, antes de finalizar la década de los cuarenta, entre los que más asiduamente se ponían delante del micrófono de Radio Club Tenerife se contaban literatos socialistas tan poco sospechosos de afección al régimen como el poeta Pedro García Cabrera y el crítico literario Domingo Pérez Minik, los cuales habían sufrido en carne propia las represalias de los golpistas tras el estallido de la guerra civil. Fue por entonces, a mediados de 1949, cuando el que fuera director del diario republicano Hoy (1932-1936) y, tras el 18 de julio de 1936, integrante de Falange Española, Eduardo Garavito (León, 2015: 506), empezó a leer a primeras horas de la noche el "Comentario del día”, un breve texto sobre algún asunto intrascendente cuyo formato sería luego imitado por las posteriores emisoras instaladas en la isla (Yanes, 2012: 150).

A mediados de los años cincuenta, entre los conferenciantes heterodoxos figuraban intelectuales que habían sufrido en carne propia la represión franquista, caso del profesor universitario Jacinto Alzola Cabrera, y el mismísimo Antonio Cubillo Ferreira, quien siete años más tarde promoviera desde Argel el Movimiento por la Autodeterminación e Independencia del Archipiélago Canario (Garí Hayek, 1992: 75-168). En un principio, el futuro líder independista canario presentaba, junto con el periodista que habría de militar en el PSOE Alfonso García-Ramos, unos "Coloquios" que, de manera explícita, enfrentaban a los valedores de dos posturas diferentes sobre un mismo tema. A título ilustrativo, el 20 de julio de 1956, la actriz argentina Pepita Serrador defendió el teatro clásico frente al literato canario Domingo Pérez Minik, que se mostró partidario del "enfrentado con los problemas del momento" de Jean-Paul Sartre y de Tennessee Williams. Al margen de estos "Coloquios", Antonio Cubillo Ferreira siguió acudiendo a los estudios de Radio Club Tenerife, al menos, hasta principios de 1957, cuando, una vez incorporado como penalista al Colegio de Abogados de Santa Cruz de Tenerife, colaboraba en la revista cultural "Perfil" (Yanes, 2012: 205 y 208). Por entonces, pues, los alardes que sobre su hoja de servicios al franquismo hacía la emisora con motivo de la celebración del 23 aniversario de su fundación, eran el discurso de una minoría que, en nada, reflejaba el talante del elemento humano que se movía en torno a esta (Yanes, 2012: 206).

\section{EL IMPACTO DE LA INAUGURACIÓN DE RADIO JUVENTUD DE CANARIAS}

La primera emisora institucional de la provincia, Radio Juventud de Canarias, inició su andadura a finales de 1955 como la estación-escuela número 57 de la Cadena azul de radiodifusión (CAR) del Frente de Juventudes. Junto al "fin primordial (de) capacitar a los jóvenes en todas las ramas del radiofonismo y el arte radiofónico", sus promotores asumieron el objetivo complementario de sacar al aire una oferta "cultural e informativ(a) para el público" (Yanes, 2009: 137), eufemismo que, como no podía ser de otra manera, se refería a una mezcolanza 
de información y opinión con propaganda al servicio de la dictadura. En pos de ello, la dirección de la CAR hacía llegar desde Madrid una serie de espacios grabados bajo las etiquetas de "informativos, culturales, educativos o recreativos", y de guiones cuya realización corría a cargo de la reducida militancia del Frente de Juventudes en la isla. Ello se debió a que esta emisora tampoco consiguió hacerse, al igual que le sucediera a Radio Club Tenerife, con una plantilla adepta al ideario franquista a pesar de su carácter institucional, como dijimos, por el antagonismo existente entre el modo de ser isleño y las tesis autárquicas y patrioteras del régimen. En consecuencia, al margen de sus cuadros directivos y de casos muy puntuales, como quien habría de asumir la jefatura de la programación, Francisco Ayala Armas, o el radiotécnico Wigberto Ramos Martínez, el grueso del personal lo conformó una hornada de jóvenes atraídos por la magia que en aquellos oscuros años anidaba en las ondas hertzianas.

Dentro de los límites de la legislación vigente, que prohibía tajantemente toda emisión hablada sin la previa autorización del organismo provincial oportuno, la estación-escuela puso en antena algunos espacios que, de una u otra manera, abordaban cuestiones locales o foráneas, evidentemente, ajenas a los temas sensibles. El margen de actuación tolerado en estos casos siempre dependió, a partes iguales, de los asuntos tratados, del talante del censor de turno y de la confianza que suscitaba el promotor de cada iniciativa. Sin duda alguna, las tres variables jugaron a favor del citado Francisco Ayala para que este mantuviera a diario en la parrilla de la programación, bajo el rubro "Radio Juventud cada 24 horas", un comentario breve de actualidad inspirado en el que Eduardo Garavito pusiera en antena en Radio Club Tenerife a finales de la década anterior. Luego, a imagen y semejanza de ambos salieron al aire "Mañana será otro día", que sucesivamente llevaron el que fuera director de la emisora Mauricio Gómez Leal, el locutor Enrique Agulló Martínez y el periodista y escritor Francisco Pimentel Santana (Cotidiano); "Mirador a la calle", del literato Juan María Arrabal; "Un paso más en la noche”, del locutor César Fernández-Trujillo; y "Radio Juventud de Canarias orienta al madrugador”, del también locutor Francisco Schumann. (02) En contraposición a Francisco Ayala, ninguno de estos seis comentaristas militó en el partido único del régimen, si bien, el temor a la originalidad, la censura y, previamente, la autocensura que todos se imponían debió homologar el contenido de todos los textos (Yanes, 2009: 31-38).

Estos espacios despolitizados, cuya fórmula se reducía a un comentario breve sobre algún acontecimiento reciente de interés preferentemente humano, alternaban con los conmemorativos de las efemérides triunfales del franquismo y los hitos históricos asumidos como propios por la ortodoxia oficial, para cuya realización el personal de la emisora se ponía a disposición del Frente de Juventudes. La fecha festiva por excelencia de la estación-escuela era el 30 de mayo, cuando, con motivo del día de San Fernando, se organizaba una serie de actos en los patios anejos a la emisora para enaltecer, con las connotaciones patrioteras de la época, a la juventud española. El resto del calendario tenía marcados, entre otros, los días 9 de febrero, por los "caídos de la juventud" a propósito de la muerte violenta del falangista Matías Montero; 1 de abril, el "día de la victoria"; 2 de mayo, en recuerdo a los héroes de la guerra de la independencia contra la invasión francesa de 1808; 17 de junio, por la reunión de Franco en el monte de Las Raíces para preparar la sublevación militar; 18 de julio, por el comienzo del llamado "glorioso Movimiento Nacional"; 1 de octubre, por la "fiesta del Caudillo"; 12 de octubre, conocido como "día de la raza" o de la Hispanidad; 29 de octubre, por la fundación de Falange Española; y 20 de noviembre, el "día del dolor" por el fusilamiento de José Antonio Primo de Rivera en 1936.

A las efemérides anuales había que añadir los eventos extraordinarios, caso de los llamados "25 años de paz", cuya celebración generó un conjunto de actos, concursos y festejos alusivos al tópico durante varios días que culminaron en el estadio Heliodoro Rodríguez López con las acostumbradas exhibiciones de coros y danzas, las tablas de gimnasia y los restantes números con los que el régimen remarcaba su carácter corporativo. En el ámbito insular, las fechas más celebradas fueron el 3 de mayo, por la culminación de la conquista castellana de las islas en 1496; y el 25 de julio por la victoria de las milicias de Tenerife contra el almirante inglés Nelson en 1797. Al margen de emitir los espacios que recibía de Madrid y de radiar los actos organizados en la isla por los mandos del Frente de Juventudes y las autoridades locales, Radio Juventud de Canarias celebraba todas estas efemérides con ciclos de conferencias propagandísticos, cuya realización implicaba al personal de la emisora, tanto locutores como técnicos del sonido, como simples operarios porque la inmensa mayoría, como dijimos, era ajena al partido único del régimen. 


\section{LA PUESTA EN MARCHA DE LAS EMISORAS DEL INTERIOR DE LA PROVINCIA}

A mediados de 1960, con la simultánea inauguración de otras tres emisoras institucionales, La Voz de la Isla de La Palma, La Voz del Valle en La Orotava y Radio Popular de Güímar, las dos primeras pertenecientes a la Cadena de Emisoras Sindicales (CES) y la última a la Iglesia, el sistema radiofónico franquista adquirió, prácticamente, su configuración definitiva en la provincia. Una minuciosa memoria sobre la andadura de los cinco primeros meses de La Voz del Valle, (03) esto es, hasta finales de 1960, resulta sumamente reveladora para entrever la información y la opinión que pusieron en antena las estaciones pertenecientes al Sindicato Vertical. Según revela el documento, la cuarta parte de la programación se dedicó a "noticias, comentarios, consignas, discursos, alocuciones, reportajes, guiones, conferencias y campañas" (Yanes y Rodríguez, 2007: 137), incluyendo los ámbitos local, comarcal, provincial y estatal. La presencia de partes tan desiguales en un mismo saco, y la prohibición de ofrecer cualquier tipo de información a iniciativa propia, nos obliga a analizar con sumo cuidado todos los indicios que hemos recopilado para reconstruir con la mayor precisión posible la realidad objeto de estudio.

Al margen de los Diarios hablados de Radio Nacional, La Voz del Valle ofrecía espacios de actualidad basados en los contenidos publicados por los periódicos y, por lo tanto, cribados previamente por la censura, tales como "Leyendo la prensa", un matinal diario en el que se leían las noticias más destacadas de El Día; o "Recorte de prensa", que estuvo en antena los días festivos, al mediodía, cuyo contenido se reducía a la lectura de un editorial o de un artículo de opinión publicado por un diario nacional, Arriba o Pueblo de Madrid, o un periódico isleño. Esencialmente informativos también eran "El puerto es lo primero", que consistía en la lectura literal de la sección homónima de El Día, sin pedir la autorización pertinente a la empresa editora ni tener problemas por ello, como era habitual en la época; "Santa Cruz cada semana", una especie de crónica sobre la capital provincial elaborada por la secretaría del Patronato Provincial de Emisoras Sindicales; y "Carretera general", otro espacio dominical centrado en los problemas que estaba generando el creciente tráfico automovilístico en la isla al calor de la bonanza económica de la década. Catalogable, en alguna medida, como informativo también era el "Diario de avisos" que, en la sobremesa, la emisora puso a disposición de todos los ayuntamientos y organismos oficiales de la zona para difundir todo tipo de información de interés general, desde los programas de los festejos populares hasta los edictos y bandos municipales, el cual también se utilizó para difundir alguna que otra noticia local imprevista y, por lo tanto, no especificada en la programación que visaba de antemano la censura, caso del fallecimiento de algún personaje relevante o de cualquier otra circunstancia que, con certeza, se sabía que no iba a contrariar a los censores.

Un aire similar, aunque alternando de manera rotatoria el centro geográfico de su interés entre los municipios de la zona, y abriendo sus contenidos a las vertientes de la actualidad ajenas a los asuntos sensibles, tenía el espacio "Nuestros corresponsales". En este caso, se trataba de una crónica de diez a quince minutos que, dedicada los lunes a La Orotava, los martes a Icod de los Vinos, los miércoles al Puerto de la Cruz, los jueves a Los Realejos, los viernes a La Guancha y los sábados a Garachico, servían por teléfono los cronistas oficiales o, en su defecto, los corresponsales nombrados ex profeso por la corporación respectiva. En los restantes días de la semana, los mismos individuos hacían llegar a la emisora por las mismas vías los acontecimientos noticiables de su localidad, caso de las visitas de las autoridades o de algún personaje destacado, las inauguraciones o los actos culturales, muchos de los cuales generaron programas extraordinarios. Al margen de los ecos de sociedad en la línea de las secciones de la prensa de la época y la información de servicio, a horas nocturnas había un último espacio en el que, bajo el rótulo "Última hora", se resumía todo lo ofrecido a iniciativa propia durante la jornada (Yanes y Rodríguez, 2007: 137-143).

Por su parte, La Voz de la Isla de La Palma puso en antena unos espacios fijos idénticos a los de su hermana sindical de La Orotava, (04) hasta en el titular, lo que resulta comprensible tanto por la pertenencia a una misma cadena como por la tendencia en toda dictadura a imitar lo establecido, en detrimento de la creatividad, para así tener la certeza de no contrariar a la superioridad. En consecuencia, la estación palmera también abordaba los avatares cotidianos del día a día de la vida local, bien a través de la típica lectura de la prensa o de la elaboración de unos guiones con las cautelas suficientes como para no dar lugar a malentendidos o a que alguna autoridad o personaje influyente se diera por aludido cuando salía a relucir algún desaguisado. Aún así, dejando entrever las rencillas entre las familias del régimen, el vespertino local Diario de Avisos de Santa Cruz 
de La Palma llegó a afirmar que tales textos: "destilan recio contenido (...) saturado de intenciones nobles expuestas sin rodeos ni atenuantes. Llamando las cosas por su nombre. Por eso, quizás, se les atraganta a determinado sector" (Yanes y Hernández, 2011: 101-113).

En el caso de Radio Popular de Güímar, un somero repaso a la dinámica de un espacio informativo que estuvo en antena un cierto tiempo, desde su elaboración hasta la recepción en la emisora y su posterior emisión, añade otros matices a las penurias que sobrellevaba la radio española en la dictadura franquista. Redactado por el periodista del rotativo La Tarde, José Manuel Pérez Borges, en la capital provincial en base a las fuentes oficiales y la prensa local, el propio autor llevaba personalmente el contenido en un sobre a la parada de las guaguas de Santa Cruz a primeras horas de la mañana para hacerlo llegar, a través de un microbús de pasajeros, al municipio de Güímar. Luego, tras el ensayo pertinente, los locutores procedían a su lectura al mediodía, después del Diario hablado, centrando todo su esfuerzo en la forma, en la dicción correcta de los vocablos, porque el fondo, al margen de carecer de la virtud de la inmediatez que es la más preciada de las ondas hertzianas, era un territorio vedado para ellos. A su vez, cuando José Manuel Pérez Borges pasaba por la emisora, sus críticas se limitaban a los errores de vocalización que había percibido al escuchar el espacio por la radio porque, como dijimos, este era el único campo susceptible de mejora ante la ausencia del más mínimo margen de maniobra para elaborar el contenido. El contenido de otro espacio similar titulado "Microcomentario", se reducía a una breve perorata escrita en medio folio que, sin connotación ideológica alguna, (05) tampoco aportaba, por las razones disuasorias comentadas, idea original alguna al tema tratado.

En las tres emisoras ajenas a la capital provincial, los guionistas de estos breves espacios que, dentro del exiguo resquicio dejado por la intolerancia del censor de turno, basculaban entre la información y la opinión, tampoco se distinguieron por militar en el partido único del régimen. En el caso de La Voz del Valle, aunque el director nominal era, como en toda estación sindical, el delegado del Sindicato Vertical de la comarca, el alma máter de toda la programación, incluyendo la que nos ocupa, fue el sacerdote José Siverio, cuyas preocupaciones intelectuales giraban, al margen de la fe católica, en torno al humanismo, la música y, como titulado por la Escuela Oficial de Periodismo de Madrid, la comunicación social. En Radio Popular de Güímar, su director, el párroco Prudencio Redondo Camarero, sólo llevaba la parte religiosa, mientras los contenidos restantes, incluidos los aquí estudiados, estaban a cargo del sector seglar de la localidad implicado en la empresa, (06) cuya vinculación era mucho más estrecha con la Iglesia que con el régimen. En el caso específico del autor del "Microcomentario" citado líneas atrás, Antonio Medina Ortega, tenemos a un joven estudiante, y futuro profesor, de Químicas de la Universidad de La Laguna cuya ideología cristalizaría luego en torno a los valores del socialismo. Aunque la realidad de La Voz de la Isla de La Palma fue algo diferente porque en su área de cobertura fue donde más había calado la doctrina falangista dentro del archipiélago en respuesta a la radicalización del proletariado en la II República (Cabrera, 1991: 526-529), tanto el contenido como las fuentes y el perfil de los artífices de estos espacios tampoco difirieron de los homólogos de su hermana sindical de La Orotava, incluido el fuerte tono religioso de toda la parrilla de la programación que, a la postre, dio cuerpo a la ideología dominante de la radiodifusión canaria durante el franquismo. (07)

En definitiva, las tres emisoras reclutaron al grueso de sus plantillas y colaboradores externos en la clase media-baja de sus localidades respectivas, cuyos miembros tenían una vinculación menor con la Iglesia que las élites. Junto a dicha extracción social, los otros rasgos definitorios del colectivo fueron la juventud, el haber cursado, o estar cursando, el bachillerato y, en algún caso, estudios universitarios, la titulación en diplomaturas como Magisterio, el ejercicio de una profesión liberal y, sobre todo, el interés por la cultura y la comunicación. Bajo tales premisas, mientras el grueso de los guionistas fueron periodistas, maestros o empleados en el sector servicios, los técnicos eran radioaficionados autodidactas que, en base a una formación adquirida en algún taller de radioelectricidad o mediante cursos por correspondencia, tenían los conocimientos suficientes como para solventar los problemillas que a diario generaban los artesanales equipos emisores. En consecuencia, los militantes de FET y de las JONS se redujeron a las cúpulas de las dos emisoras sindicales y a algún otro que, como el radiotécnico más capacitado de la isla, Wigberto Ramos Martínez, fueron la excepción que confirma la regla de la desvinculación del elemento humano del régimen franquista. 
En las áreas de cobertura de las distintas emisoras hubo ocasiones en las que, ante algún acontecimiento local relevante y poco dado a malentendidos, se relajaron los controles hasta el extremo de permitir al personal el ejercicio de su profesión con ciertas dosis de espontaneidad. Los casos más frecuentes fueron las visitas de alguna autoridad provincial o estatal, cuando los locutores y corresponsales cubrían el recorrido del político de turno, muchas veces, improvisando sobre el guión que previamente habían llevado a sellar a la delegación del Ministerio de Información y Turismo con toda la programación del día para recibir el preceptivo visto bueno antes de su emisión. Otro tanto sucedió con los asuntos de interés humano y, en particular, con las eventualidades sobrevenidas que trastrocaron el discurrir del día a día, en las que a menudo las ondas hertzianas rebasaron sus funciones convencionales para convertirse en una de las herramientas más eficaces para gestionar tales crisis. Pero estas incursiones en la inmediatez informativa fueron excepcionales en una época en la que la copia de lo que otros hacían para ir sobre camino seguro y la autocensura para evitarse problemas eran los rasgos más característicos de los modos de hacer radio en España. Para ilustrar las interioridades de estas coyunturas locales, nada mejor que detenernos en algunos de los episodios vividos en las emisoras ajenas a la capital provincial.

La Voz de la Isla de La Palma tuvo la oportunidad de demostrar las virtudes de la difusión continua e indiscriminada de las ondas hertzianas frente al espaciamiento de las entregas físicas, cada 24 horas, de la prensa diaria, con motivo de la que hasta ahora ha sido la última erupción volcánica de las Islas Canarias, la del Teneguía entre el 26 de octubre y el 18 de noviembre de 1971. Así, mientras la emisora informaba puntualmente del impacto del magma en los sembrados y las infraestructuras de la zona afectada, varios radioaficionados en colaboración con sus colegas emigrados en Venezuela se encargaban de tranquilizar a la colonia palmera establecida en aquella república con el desmentido de las alarmantes noticias ofrecidas por los periódicos venezolanos sobre el suceso. A tal fin, los mensajes que a través de las ondas llegaban de Canarias eran trasladados de continuo a Radio Caracas, desde donde se retransmitían para toda Venezuela, cosa que también hizo La Voz de la Isla de La Palma con los recibidos allende los mares, lo que habilitó una interconexión a través de la cual fluyó ininterrumpidamente la información entre ambas orillas del Atlántico. Mientras tanto, Diario de Avisos de Santa Cruz de La Palma se tenía que conformar con ofrecer un resumen de los hechos acaecidos el día anterior con un tono esencialmente explicativo a unos lectores que ya estaban al corriente de lo sucedido (Yanes y Hernández, 2011: 105-107). Por consiguiente, en tanto en cuanto el volcán permaneció activo, la radio tejió con el beneplácito del régimen y, dado el escaso alcance de la señal, el apoyo de los radioaficionados, los cauces más eficaces para ofrecer con la celeridad deseable toda la información demandada por la ciudadanía ante la incertidumbre reinante.

En el caso de La Voz del Valle, una de las coyunturas más propiciatorias para tales quehaceres llegó con el accidente de aviación que, a mediados de marzo de 1964, se produjo en el aeropuerto de Los Rodeos por la falta de visibilidad causada por la neblina, con el trágico balance de 29 muertos y 19 heridos. Dada la cercanía del lugar de los hechos, la emisora norteña envió a un locutor y a un técnico con uno de los vetustos magnetófonos Ferrograph de la época a cuestas, los cuales grabaron sobre el terreno un reportaje con el que, luego, informaron de la tragedia con datos originales (Yanes y Rodríguez, 2007: 140). Otro tanto sucedió a Radio Popular de Güímar con motivo del derrumbe, a inicios de febrero de 1963, de una parte del viejo convento que por entonces albergaba al ayuntamiento y al juzgado del municipio de Granadilla (Yanes, 2007: 149-150), cuando un gentío que había acudido a tramitar el documento nacional de identidad se había aglomerado en el segundo piso del inmueble para resguardarse de la lluvia, con el saldo de 22 fallecidos y más de un centenar de heridos. En este caso, conforme avanzó la tarde, la emisora sureña ofreció los detalles que fue recibiendo a través del teléfono para, al día siguiente, enviar a un locutor y a un técnico para grabar los testimonios con los que, luego, elaboró un programa informativo de producción propia.

\section{LAS COYUNTURAS INFORMATIVAS GENERALES}

También hubo acontecimientos internacionales con tan honda repercusión como para propiciar que todas las emisoras se adentraran, con las consabidas dificultades, en las labores informativas por cuenta propia. llustrativa de los riesgos a los que estaba expuesto el personal en tales coyunturas fue la reprimenda que recibió el jefe de programación de La Voz del Valle, el sacerdote José Siverio, a propósito del asesinato del presidente de los Estados Unidos, John Fitzgerald Kennedy, en noviembre de 1963, coyuntura en la que, 
paradójicamente, los censores fueron muy permisivos en todo el estado (Díaz, 1992: 376). Pues bien, tras leer los primeros detalles que al respecto había publicado el rotativo El Día, José Siverio consideró oportuno redactar, ante la profunda conmoción causada por el magnicidio, un breve resumen con los datos conocidos para que un locutor lo leyera a primera hora. Nada más salir al aire el contenido de la escueta nota, a pesar de la asepsia del tema, de la condición sacerdotal del responsable del hecho y de las garantías de la fuente utilizada porque había pasado todos los controles establecidos para la prensa, el susodicho recibió una llamada telefónica de la secretaría del Gobierno Civil para recordarle que debía abstenerse de dar todo tipo de información por la emisora. (08) Aún así, conforme avanzaron los años sesenta y, sobre todo, desde la ley Fraga de 1966, estas incursiones informativas a iniciativa propia que abordaban, desde la llegada del hombre a la Luna en el estío de 1969 a la visita del presidente estadounidense Gerald Ford a España a finales de 1973, se hicieron cada vez más frecuentes.

Sin duda alguna, la coyuntura en la que todas las emisoras isleñas resultaron más útiles a la ciudadanía data del 29 de julio de 1967, cuando a últimas horas de la tarde un fuerte terremoto sacudió Caracas, la ciudad en la que residía la colonia canaria más numerosa del exterior. Nada más llegar las primeras noticias del suceso a través del Diario hablado nocturno de Radio Nacional de España, la incertidumbre se apoderó de la población al comprobar que había perdido el contacto telefónico y telegráfico con sus familiares emigrados por los destrozos causados en las infraestructuras por el seísmo. En tal tesitura, y al igual que sucediera cuatro años más tarde en la isla de La Palma a propósito de la erupción del Teneguía, el personal de todas las emisoras se valió de los radioaficionados para montar, sin problema alguno, un tejido comunicativo con la república venezolana que les permitió dar información puntual sobre cada uno de los afectados, de tal manera que cuando, días más tarde, se restablecieron las comunicaciones entre las dos orillas del Atlántico, todo el mundo ya estaba al corriente de la suerte de sus seres queridos (Yanes y Rodríguez, 2007: 140-141; Yanes y Hernández, 2011: 106).

También hubo ocasiones en las que, ante la enorme expectación despertada entre la población canaria por alguna circunstancia, la censura se mostró más permisiva de lo habitual con algunos acontecimientos internacionales catalogables como delicados. En estos casos, más que acallar a las emisoras, se prefirió concentrar todos los esfuerzos en el control de la información que llegaba del exterior para erradicar la circulación de los datos indeseables, lo que a veces generó versiones parciales o tergiversadas de algunos hechos. Ilustrativo fue el secuestro del trasatlántico portugués Santamaría en enero de 1961 por un militar disidente de la dictadura de Oliveira Salazar, Enrique Galvao, a poco de partir de Venezuela rumbo a Canarias con un numeroso contingente de isleños a bordo. Explicado en todas las emisoras como un "acto terrorista" más, tanto el secuestro en sí como la subsiguiente liberación de los rehenes fueron seguidos con enorme expectación en el archipiélago, al igual que la posterior llegada de los paisanos liberados a Santa Cruz de Tenerife en el trasatlántico Vera Cruz, la cual fue cubierta por todas las emisoras en el mismo muelle sin problema alguno. Para calibrar hasta qué extremo llegó el grado de desinformación de la población canaria sobre aquellos hechos, basta con traer a colación que en el imaginario colectivo del municipio de Güímar el mote Galvao se utilizó para tildar a las personas de malvadas (Yanes, 2007: 146).

Los detalles de la labor reporteril realizada por el personal de La Voz del Valle al desembarcar los pasajeros del Vera Cruz en el puerto de la capital provincial, resultan sumamente ilustrativos para entrever, al margen de las dificultades que suponía tener encima la espada de Damocles del omnipresente censor, la dosis de imaginación que había que poner en la época para paliar las limitaciones de los medios disponibles. En efecto, cuando el locutor y el técnico enviados por la emisora norteña se disponían a entrevistar a varios de los protagonistas del suceso en medio del gentío que había en el muelle, se encontraron con la desagradable sorpresa de no poder hacerlo porque en el lugar no había corriente de 110 voltios, sino de 220. Lejos de resignarse a regresar de vacío a La Orotava, ambos consiguieron que un colega de Radio Juventud de Canarias les facilitara una cinta con varias entrevistas que, en los días previos, habían emitido con las declaraciones de diversas autoridades. Entregado el material al jefe de programación de La Voz del Valle, este dispuso que fueran emitidos los contenidos sobre un fondo de bullicio humano creado por todo el personal de la emisora en el estudio, con voces e, incluso, sonidos de bocinas parecidas a las de los buques, para recrear el ambiente que se había vivido en el muelle y, así, trasladar el desembarco tal y como se había vivido in situ. (09) 


\section{LAS MEJORAS CONTEXTUALES EN EL TARDOFRANQUISMO}

A mediados de septiembre de 1965, a seis meses vista de la promulgación de la llamada ley Fraga de 1966, la prensa destacó la celebración, "por primera vez en nuestro archipiélago", de una "rueda de prensa en Televisión en Canarias cara al público", en lo que fue un anticipo de la inminente, aunque leve, distensión de la mordaza que siempre atenazó la labor periodística en el franquismo. El "personaje interrogado" fue Carlos Robles Piquer, el por entonces director general de Información, quien se sometió a las preguntas de una decena de periodistas en representación de los cinco diarios de ambas provincias, las dos Hoja del Lunes, las emisoras privadas e institucionales de las capitales provinciales y el Centro emisor del Atlántico de Radio Nacional de España. Los controles eran todavía tan rígidos que el novedoso espacio, cuya duración se prolongó hasta casi una hora, fue emitido en diferido al día siguiente (Yanes, 2012: 263 y 264), sin que por ello perdiera expectación ante una audiencia que no estaba acostumbrada al dinamismo de tales formatos.

Sería a partir de 1966, con la añadidura de las tímidas mejoras introducidas por la ley Fraga a la bonanza económica, cuando la presión del asfixiante corsé que ahogaba la circulación de la información en el país comenzó a ceder ya sin solución de continuidad en la expansiva coyuntura tejida por el boom turístico. Los nuevos tiempos, sin embargo, se circunscribieron, al igual que en el resto de España, a los núcleos más urbanizados y a los enclaves costeros de sol y playa, porque los restantes siguieron anclados en las tradicionales estructuras caciquiles y rurales. En el sistema radiofónico insular, el escaso predicamento que tradicionalmente había tenido el ideario del régimen entre el personal de las emisoras, como en el conjunto de la sociedad, hace explicable que la celebración del día de San Fernando en Radio Juventud de Canarias quedara reducida a finales de la década a un acto testimonial que pronto, antes del óbito del general Franco, pasó a mejor vida. En la otra emisora institucional sobreviviente en la provincia, La Voz de la Isla de La Palma, cuya área de cobertura fue la más proclive al ideario franquista, aunque es verdad que todavía se celebró la fundación de Falange a tres semanas vista del fallecimiento del dictador, no es menos cierto que el acto se redujo a una simple conferencia del delegado provincial de Familia y de Acción Política y Participación (Yanes y Hernández, 2011: 113).

Mientras tanto, Radio Club Tenerife había empezado a emitir, a finales de enero de 1972, el primer informativo nocturno tolerado por el Ministerio de Información y Turismo a la cadena SER, Hora 25, cuyos contenidos basaba en la información del Diario hablado de Radio Nacional de España. Dos años más tarde, con el respaldo de una audiencia masculina nada desdeñable a pesar de la competencia de la televisión (Aguado, 1992: 202208), el innovador espacio estaba en antena todas las noches entre las 22:30 y las 12:00 de la noche, con la primera parte dedicada a la información general, la intermedia a los deportes con el gancho del irreverente José María García y la tercera a una entrevista en profundidad (Balsebre, 2002: 372-393). El ejemplo sirvió para que el elemento humano de esta y de las restantes emisoras isleñas se soltara cada vez más y acentuara sus incursiones, aunque todavía con muchas cautelas, en el ejercicio de la profesión periodística. En lo que a la otra estación de la capital provincial se refiere, Radio Juventud de Canarias, desde finales de la década de los sesenta estaba en manos de una pléyade de jóvenes ajenos cuya única motivación era aprender con la práctica para hacer del medio su profesión, entre los que figuraría el periodista deportivo Domingo Álvarez, el actual director del Centro emisor del Atlántico de Radio Nacional de Canarias.

\section{CONCLUSIONES}

Todos los datos recabados sobre las dos variables analizadas en las emisoras de la provincia de Santa Cruz de Tenerife, el contenido de los programas de producción propia que, en alguna medida, tuvieron un tono informativo, y el perfil ideológico de sus guionistas, guardan coherencia con el rechazo social de las tesis autárquicas de la dictadura y, por ende, con la escasísima implantación de Falange en el archipiélago. En efecto, a poco que se relajaron los fuertes controles que sobre el medio establecieron los insurrectos desde el golpe de Estado, los breves comentarios sobre la actualidad objeto de nuestro estudio empezaron a menudear a iniciativa, salvo en contadísimas ocasiones, de los periodistas, intelectuales y colaboradores ajenos al partido único, toda vez que la militancia de este brillaba por su ausencia en Canarias. En el proceso, los contenidos perdieron cada vez más el afán proselitista heredado de la conflagración fratricida sin que por ello ganaran utilidad social porque siempre versaban, ante el poder disuasorio de la censura, sobre asuntos vacuos o irrelevantes. Es más, tales espacios generaron con harta frecuencia más desinformación que información por el 
uso exclusivo de las fuentes oficiales y la autocensura que, instintivamente, se imponían los guionistas.

Paralelamente, el decurso de los años ahondó en la brecha abierta entre los círculos que pudieron acceder a una información de actualidad con un mínimo de rigor y el grueso de la población que, indefensa ante la versión oficial de los hechos, permaneció desinformada en aquellas cuatro décadas. Nos referimos, en el primer caso, a la raquítica minoría que pudo permitirse el lujo de adquirir un buen aparato receptor y la antena adecuada (cosa que no estuvo al alcance de cualquiera hasta bien avanzados los años sesenta) para, así, poder sintonizar la llamada Radio Pirenaica o una estación extranjera que ofreciera puntos de vista alternativos a los del régimen; y, en el otro, a la inmensa mayoría de la población que sólo tenía a mano los canales oficiales de la dictadura. El amordazamiento de la censura en una sociedad tan dependiente y abierta al exterior como la canaria hizo que, ante la masiva desafección al ideario franquista, el referente ideológico del discurso producido internamente por la radiodifusión isleña se escorara cada vez más hacia el catolicismo en detrimento del falangismo, hasta dejar a este recluido en los programas de producción externa que llegaban de Madrid. Todo ello también conllevó la uniformización de todas las emisoras, desde la privada Radio Club Tenerife a la estación-escuela del Frente de Juventudes, pasando por la católica Radio Popular de Güímar y las sindicales La Voz del Valle de La Orotava y La Voz de la Isla de La Palma, ante el fuerte ascendiente que en todas ellas tuvo la Iglesia.

Aunque la investigación ha dejado en evidencia que las cinco emisoras de la provincia occidental del archipiélago eran bocas de salida de un mismo mensaje de producción propia que, por su redundancia, acentuó la desinformación entre los oyentes, no es menos cierto que también ha puesto de relieve los inestimables servicios que todas ellas prestaron a la sociedad isleña en la gestión de las crisis sobrevenidas por algún suceso o imprevisto de repercusión extra-insular. Tal fue lo que sucedió a propósito de la erupción del volcán Teneguía en La Palma o del terremoto de Caracas, cuando el sector tejió en colaboración con los radioaficionados, en aquellos oscuros años en los que a la precariedad de la infraestructura comunicativa se unía la censura franquista, unos ágiles cauces informativos para atender las demandas de información de las familias isleñas asentadas en las dos orillas del Atlántico. Probablemente, ante la ausencia de información "veraz" sobre la actualidad, este tipo de iniciativas constituyó el capítulo informativo de la radiodifusión franquista más útil para la sociedad insular.

\section{REFERENCIAS BIBLIOGRÁFICAS}

AguAdO MONJAS, G. (1992). La Televisión Pública en Canarias. Tesis doctoral. Universidad Complutense, Departamento de Periodismo IV, Madrid.

AGUIRRE ROJAS, C. A. (2014). Microhistoria italiana: modo de empleo. Barcelona: Montesinos.

BALSEBRE, A. (2002). Historia de la Radio en España (1939-1985). Madrid: Cátedra.

CABRERAACOSTA, M. Á. (1991). La Segunda República en las Canarias Occidentales. Santa Cruz de Tenerife: Centro de la Cultura Popular Canaria.

DÍAZ, L. (1992). La radio en España, 1923-1993. Madrid: Alianza Editorial.

DÍEZ PUERTAS, E. (2008): “La censura radiofónica en la España nacional (1936-1939)”. Zer, vol. 13, n² 24, pp. 103-124.

GARI HAYEK, D. (1992). Historia del Nacionalismo Canario. Santa Cruz de Tenerife: Editorial Benchomo.

GUERRA PALMERO, R. (2006). Sobrevivir en Canarias (1939-1959). Racionamiento, miseria y estraperlo. Santa Cruz de Tenerife: Ediciones Idea.

LEÓN ÁLVAREZ, A. (2015). La institucionalización del franquismo en las Canarias occidentales (1936-1961).

Tesis Doctoral. Universidad de La Laguna, Departamento de Geografía e Historia. 
MACÍAS HERNÁNDEZ, A.; RODRÍGUEZ MARTÍN, J. A.: La economía contemporánea, 1820-1990. En:

BĖTHENCOURT, A. (1995). Historia de Canarias. Las Palmas: Cabildo de Gran Canaria, pp. 369-398.

YANES MESA, Julio Antonio (2003). Historia del Periodismo Tinerfeño, 1758-1936. Una visión periférica de la Historia del Periodismo Español. Santa Cruz de Tenerife: Centro de la Cultura Popular Canaria.

- (2007). Los orígenes de la COPE en Canarias. "Radio Popular de Güímar», 1960-1969. Santa Cruz de Tenerife: Ediciones Baile del Sol.

- (2009). Las ondas juveniles del franquismo. «Radio Juventud de Canarias», 1955-1978. Santa Cruz de Tenerife: Ediciones Baile del Sol.

- (2012). La radiodifusión privada en Canarias durante el franquismo. "Radio Club Tenerife», 1939-1975. Canarias: Ediciones Densura.

- (2011). La propaganda radiofònica de l’Espanya nacional a Canàries Durant la Guerra Civil, 1936-1939. Anàlisi, $n^{\circ} 41$ (2011), pp. 101-116.

- y RODRÍGUEZ BORGES, Rodrigo Fidel (2007). La radiodifusión sindical del franquismo. "La Voz del Valle» en las Islas Canarias, 1960-1965. La Orotava: Ayuntamiento de La Orotava, Cabildo de Tenerife y Dirección General del Libro, Archivos y Bibliotecas del Gobierno de Canarias.

- y HERNÁNDEZ CABRERA, Edmundo (2011). "La Voz de la Isla de La Palma», 1960-1978. La radiodifusión del sistema comunicativo más singular de Canarias en el franquismo. La Palma: Ediciones Alternativas

(01) Debido a la importancia de esta variable en la investigación, precisamos su magnitud con estos datos: a finales de la guerra civil, el gobernador civil Vicente Sergio Orbaneja afirmaba que: «el partido (Falange) nació aquí (en Canarias) el mismo día del Alzamiento Nacional, pues antes tenía solo unos 14 afiliados»; y a inicios de los años cincuenta, uno de sus sucesores en el gobierno civil, Luis Rosón Pérez, denunciaba «la falta de vocación política que era pronunciada en esta provincia». En todo ello redunda la principal aspiración de la "clase dominante» isleña después de la etapa excepcional del Mando Económico durante la II Guerra Mundial: la recuperación de los puertos francos, hasta el extremo de convertir su consecución en el objetivo prioritario que, en 1953, se trazó el I Congrego provincial de FET y de las JONS, en abierta contradicción con las tesis autárquicas del ideario falangista (León, 2015: 179, 393, 369 y 403).

(02) Agradecemos los detalles facilitados por los propios locutores César Fernández-Trujillo y Enrique Agulló en sendas entrevistas efectuadas en febrero de 2010.

(03) Archivo Histórico Provincial de Santa Cruz de Tenerife, Fondo Sindicatos, Secretaría, La Voz del Valle, ECS $n^{\circ} 25$, documento fechado en enero de 1961.

(04) Archivo Histórico Provincial de S/C de Tenerife, Delegación de S/C de La Palma, Secretaría, Correspondencia, Caja 3298, Memoria del año 1965.

(05) Entrevistas efectuadas a los locutores Antonio Medina Ortega y Rosa Avelina Cruz Alberto en junio de 2007.

(06) Archivo particular del sacerdote Prudencio Redondo Camarero, informe interno de la comisión diocesana de radio, cine y televisión de la Diócesis Nivariense.

(07) Al respecto, tenemos prácticamente concluido un trabajo bajo el título «El catolicismo como sucedáneo ideológico en la radiodifusión de las Islas Canarias durante el franquismo» que pronto saldrá a la luz.

(08) Agradecemos estos detalles al propio José Siverio Pérez en la entrevista efectuada en febrero de 2007. 
(09) Datos facilitados por el técnico Álvaro Morales Jorge y el locutor Carlos Argüelles García en sendas entrevistas celebradas en enero de 2007.

\section{BREVE SEMBLANZA DEL AUTOR}

Julio Antonio Yanes Mesa (Islas Canarias, 1951), es doctor en Historia (1991) y Periodismo (2001) por la Universidad de La Laguna, donde ejerce como profesor titular de la Facultad de Ciencias Políticas, Sociales y de la Comunicación. Sus líneas de investigación están centradas en el privilegiado laboratorio que, desde perspectivas internacionales, configura el microespacio del archipiélago canario en este mundo cada vez más globalizado. Tiene dos tramos de investigación reconocidos por la CNEAI en 2006 y 2012.

Ámbitos. Revista Internacional de Comunicación, n.34, edición de otoño, 2016.

Recibido: 15/07/2016

Aprobado: 21/08/2016 